\title{
Understanding Child Feeding Practices of Vietnamese Mothers
}

Lynn M. Babington

Fairfield University, Ibabington@fairfield.edu

B. Patel

Follow this and additional works at: https://digitalcommons.fairfield.edu/nursing-facultypubs

Copyright 2008 Lippincott, Williams, \& Wilkins

This is the author's version of a work that was accepted for publication in American Journal of Maternal Child Nursing. Changes resulting from the publishing process, such as peer review, editing, corrections, structural formatting, and other quality control mechanisms may not be reflected in this document. Changes may have been made to this work since it was submitted for publication. A definitive version was subsequently published in American Journal of Maternal Child Nursing, 33(6), 2008. DOI: 10.1097/01.NMC.0000341259.03298.26

\section{Peer Reviewed}

\section{Repository Citation}

Babington, Lynn M. and Patel, B., "Understanding Child Feeding Practices of Vietnamese Mothers" (2008). Nursing and Health Studies Faculty Publications. 14.

https://digitalcommons.fairfield.edu/nursing-facultypubs/14

\section{Published Citation}

Babington, L., \& Patel, B. (2008). Understanding Child Feeding Practices of Vietnamese Mothers. American Journal of Maternal Child Nursing, 33(6), 376-381.

This item has been accepted for inclusion in DigitalCommons@Fairfield by an authorized administrator of DigitalCommons@Fairfield. It is brought to you by DigitalCommons@Fairfield with permission from the rightsholder(s) and is protected by copyright and/or related rights. You are free to use this item in any way that is permitted by the copyright and related rights legislation that applies to your use. For other uses, you need to obtain permission from the rights-holder(s) directly, unless additional rights are indicated by a Creative Commons license in the record and/or on the work itself. For more information, please contact digitalcommons@fairfield.edu. 
Running head: Vietnamese Child Feeding Practices

\section{Understanding Child Feeding Practices of Vietnamese Mothers}

Funding Sources: This study was funded in part by a grant from the Bouve College of Health Sciences, Northeastern University, Boston, MA 


\section{Callouts:}

Key Words: obesity; child feeding; immigrant; Vietnamese; focus groups 


\begin{abstract}
Purpose: The purpose of this research was to understand the feeding practices, knowledge and nutritional beliefs of Vietnamese mothers with young children who are recent immigrants to the US.

Study Design and Methods: This exploratory, descriptive study used a focus group design to provide qualitative data. Twelve Vietnamese mothers of children under the age of 5 participated in a one-hour focus group discussion (in Vietnamese) facilitated by a Vietnamese nutritionist and the Principle Investigator (PI).

Results: The study resulted in a description of how Vietnamese mothers feed their children and their beliefs regarding the health implications of childhood obesity. Clinical Implications: Findings from this study help increase our understanding of child feeding practices of mothers. This knowledge can be used by nurses to develop culturally appropriate interventions for immigrants from Vietnam aimed at preventing childhood obesity. Interventions that consider the effects of acculturation will be more effective when targeted to parents of young children than interventions focused on treatment of obesity in later years.
\end{abstract}




\section{Introduction}

\section{Obesity in Immigrant Children}

Rates of childhood obesity among the general population are alarmingly high and are highest in ethnic minority, low income, and immigrant communities (Kumanyika \& Grier 2006). The most recent US Census Bureau data estimate that 28 million foreignborn persons reside in the US, representing $10.4 \%$ of the total population (U.S. Census, 2002). Immigrant households have a greater number of children under 18 than nativeborn households (U.S. Census, 2002). One in five children in the US today is from an immigrant family (Hernandes, 1999). Clearly, the health of our immigrant youth will greatly impact the health of our nation.

An interesting and poorly understood phenomenon is the rise in obesity and diabetes in the children of recent immigrants. Vietnam is one of the top ten countries of birth for foreign-born US residents (U.S. Census, 2006). The 2000 Census reported that 1.2 million Vietnamese immigrants live in the US and 361,668 are children under 18. (US Census Bureau 2006). Children of Asian immigrants are the fastest growing ethnic group of obese children (Thorpe, et al., 2004). This is surprising given that Asian adults have a low incidence of obesity (Hernandes, 1999). Studies where data are available (New York and Massachusetts) report that Vietnamese immigrants are less overweight (defined as body mass index greater than or equal to 85\%), than other groups; yet Asian children in New York are twice as likely to be obese than their parents (Thorpe, et al., 2004; Santora, 2006). This pattern is exhibited in Massachusetts also. The Women Infant and Children (WIC) program data collected in the Massachusetts Pediatric Nutritional Surveillance System showed that $25.3 \%$ of Asian children under age 5 are at-risk for 
overweight or are overweight, even though Asian women are less likely to be overweight (Weicha, Fink, Weicha, \& Herbert, 2001). These findings are consistent with current trends in the US where 30\% of children are found to be overweight or obese (Paxson, Donahue, Orleans, \& Grisso, 2006). Thus, with a large share of Massachusetts Asian immigrants being from Vietnam and the high birth rate in Vietnamese immigrants $(8,182$ births between 2000-2005), an intervention to prevent childhood obesity in Vietnamese children is warranted.

\section{Why Should We Care about Childhood Obesity?}

Over the past three decades, the number of children considered overweight or obese has doubled, from 15\% in the 1970s to $30 \%$ today (Paxson, Donahue, Orleans, \& Grisso, 2006). Childhood obesity has captured public attention and become a major topic in the evening news. In 2005, the Institute of Medicine, in its report, Preventing Childhood Obesity: Health in the Balance, used the terms "epidemic," dangerous," and "alarming" to describe the current situation and called for the prevention of childhood obesity to be a national priority (Ebbleing, Pawlak, \& Ludwig, 2002;

Daniels, 2006). Based on data from the1999-2002 National Health and Nutrition Examination Survey, one in five children ages 2-5 and one in three children ages 6-11 met criteria for being overweight or at risk for overweight.

Childhood obesity has physical and psychological health implications (Daniels, 2006). The immediate and long-term physical ramifications of obesity in children and adolescents include cardiovascular problems such as hypertension, high triglycerides, hyperlipidemia and high cholesterol (Goran, Ball, \& Cruz, 2003), non- insulin dependent diabetes (Goran, Ball, \& Cruz, 2003), increased growth during puberty followed by 
stunting; early onset of puberty in females and early menarche, asthma (Baruffi, Hardy, Waslien, Uyehara, \& Krupitsky, 2004; Myers, \& Vargus, 2000), pancreatitis, gall bladder disease, and polycystic ovary syndrome (Myers, \& Vargus, 2000). Psychological implications range from low self-esteem and depression resulting in behavior problems at school and at home (French, Story,\& Perry, 1995; Strauss, 2000) to being victims or perpetrators of bullying behaviors (Janssen, Crawford,\& Boyce, 2004).

Childhood obesity and diabetes are increasingly observed in younger age groups (Keiss, Bottner, Bluher, Raile, Galler, \& Kapellen, 2004). This trend is threatening the public health of our nation because childhood obesity is strongly correlated with obesity in adulthood, and adult obesity is a significant morbidity factor. Perhaps even more troubling is the Center for Disease Control and Prevention's Pediatric Nutrition Surveillance System report, which found that obesity during infancy persists throughout preschool years (Center for Disease and Prevention, 1998). Thus, interventions to prevent obesity in infancy can be predicted to decrease obesity in children and ultimately in adults.

The increase in childhood obesity is also an economic issue. While the cost estimates of treating obese children remain relatively small, they are rapidly rising. The Brookings Institute estimates that the costs of treating adult obesity-related health problems may now exceed the costs of treating health problems related to smoking (Sturm, 2002). Preventing childhood obesity from developing may be the key to stemming the obesity epidemic in this country. We know that parents have a major influence on the weight of infants and young children and the development of eating patterns. 


\section{Early Prevention with Families}

\section{Parents play a critical role in preventing childhood obesity and are the} exclusive agents of change in the treatment of childhood obesity (Golan, Weizman, Apter \& Fainara,1998; Ritchies, Welk, Styne, Gersteir \& Crawford, 2005; National Association of Pediatric Nurse Practitioner, 2006; Lindsay, Sussner, Kim \& Gortmaker, 2006). Not only do parents control the food young children eat, they also help children develop and maintain healthful eating habits. Parents directly determine children's physical and social environment and indirectly influence their behaviors, habits and attitudes about food (Golan, Weizman, Apter \& Fainara,1998). During the first years of life, children learn an enormous amount about food and eating in the family context and are shaped by parents' own food preferences and selections, which are influenced largely by the cultural context (Birch \& Fisher, 1998; Birch \& Davidson, 2001). Individual differences in the physiologic regulation of energy intake appear as early as the preschool years, suggesting that parents may have an enormous influence on these differences (Birch \& Fisher, 1998). Particularly in the early years of a child's life, parents have a direct role in providing experiences that encourage the child's control over food intake (Birch \& Davidson, 2001). Despite children's predisposition to respond to the energy content of foods in controlling intake, children also respond to parents' attempts to control food intake (Birch \& Davidson, 2001). Parents who control or restrict a child's access to certain foods might actually enhance the desire for the restricted foods, causing an imbalance in a child's normal internal cues to self-regulate hunger leading to an increase in food consumption. Birch and colleagues' research suggests that children under the age of 5 actually have the capacity to regulate energy intake when they are 
provided with a variety of food choices, do not have any foods restricted, and where parental modeling of healthy eating takes place (Birch \& Fisher, 1998; Birch \& Davidson, 2001).

This study is part of a larger program of research aimed at developing and testing a culturally appropriate behavioral and educational intervention aimed at preventing childhood obesity. Understanding child feeding practices of Vietnamese immigrant mothers along with their knowledge regarding childhood obesity and its health implications are important and will inform the development of an intervention that will be tested with this group of immigrant mothers.

\section{Study Design and Methods}

\section{Specific Aims}

The purpose of this research was to understand feeding practices and nutritional beliefs of Vietnamese immigrant mothers. This study, using focus group methodology, identified Vietnamese mothers' views related to the introduction of food to infants and feeding practices for young children along with knowledge and beliefs related to the causes and health implications of childhood obesity.

The research questions for this study included:

1. What are the feeding practices for infants and young children used by Vietnamese mothers?

2. What do Vietnamese mothers know about healthy size and weight and ideal diet for young children?

3. What do Vietnamese mothers know about the causes and health implications of childhood obesity? 


\section{Methods}

Design and Setting

Little is known about Vietnamese immigrant mothers' knowledge and beliefs regarding childhood obesity and its health implications or on infant and child feeding practices. Focus group methodology was employed in this exploratory, descriptive study. Focus groups are a qualitative research tool capitalizing on group processes and interpersonal interaction to gain rich data. Focus groups serve as a useful starting point for exploratory research because they provide a means for determining how participants think and the ways in which they communicate (Bloor, Frankland, Thomas, \& Rosen, 2001, McLafferty, 2004).

A focus group was conducted with a group of Vietnamese immigrant mothers to collect data about their feeding practices for infants and young children along with their knowledge and beliefs related to healthy weight for children and the health implications of obesity. This focus group study was the first phase of a larger research project aimed at preventing childhood obesity in immigrant children. Findings from this study informed the development of a culturally appropriate behavioral and educational intervention for the prevention of childhood obesity that is currently being tested with immigrant mothers. The use of focus groups in the context of intervention development is supported by Kidd \& Parshall (2000).

The setting for data collection was a neighborhood in Boston where the majority of Vietnamese immigrants live. The study took place on a Saturday afternoon in the conference room of the Women Infants and Children (WIC) program . IRB approval for the study was obtained through Northeastern University. 


\section{Procedure}

Participants were recruited through flyers describing the study that were placed in the WIC office, local community health center and several nail salons in the neighborhood. Additionally, a Vietnamese nutritionist working in the WIC program recruited participants through word of mouth. She explained the purpose of the study and logistics to her clients.

Through an interpreter, the principal investigator (PI) described the purpose of the study, how the study would be conducted and the confidentiality inherent in the process. Additionally, participants were told that they did not have to answer any of the questions if they felt uncomfortable. Participation was voluntary. Participants also received a consent form translated into Vietnamese describing the study.

Participants joined in a 45-minute focus group session moderated by a trained Vietnamese focus group facilitator. This session took place in a community conference room in the neighborhood WIC office. Participants were asked to provide basic demographic data. Forms were available in Vietnamese. All of the participants were able to read and write in Vietnamese. Names were not collected from focus group participants.

A semi-structured set of questions was used to ensure that specific issues were examined while allowing a certain level of spontaneity for participants to expand the discussion topics. The session was audio tape-recorded. When the session was complete, participants received a gift certificate to a local Asian market.

\section{Sample}

The cohort for this study was a convenience sample of 10 mothers ages 31-44 years (mean age $=35.9)$ with at least one child (20 children altogether; mean number of 
children=2). Three women reported being single, and 7 married. Employment varied and include bank teller in a national bank, maintenance worker, babysitter, and housekeeper. All of the women reported that they worked outside of the home. The highest educational level attained was as follows: 4 college graduates and 6 high school graduates or equivalent. When asked how well they spoke and/or understood English, two said "a little", 6 answered "pretty well", one answered "fluently" and one did not answer the question. The estimated yearly income for the entire family was reported as follows; 4 reported less than $\$ 10,000 ; 1=\$ 10,001-\$ 20,000 ; 3=\$ 20,001-\$ 30,000$; $1=\$ 30,001-\$ 40,000 ;$ and $1=\$ 40,001-\$ 50,000$.

\section{Data Analysis}

The PI and graduate assistant conducted analysis. Data from the focus group were generated from field notes and audiotape. The translator transcribed the audiotape verbatim and data were reviewed by the PI for completeness and accuracy. Transcribed data were systematically analyzed, organized, and coded according to the specific aims of the study using a modified constant comparative method of analysis (Denzin \& Lincoln, 2000). Analysis was facilitated by color-coding the transcript by focus group session for ease in sorting the data into themes. Following immersion in the data, analysis focused on identification of emergent themes in accordance with the principles derived by Kidd and Parshall (2000).

A number of measures were employed to enhance the validity of this research. Audio taping the focus group discussion ensured the collection of accurate and detailed data. Data were independently coded by the PI and graduate assistant as a method to establish content validity (Lynn, 1986). Interrater reliability was used to confirm all 
themes, and an audit trail was documented throughout the process of analysis. Field notes were reviewed with the transcripts during the process. Finally the themes were validated and confirmed with the Vietnamese-speaking focus group facilitator. The data were continually analyzed to enhance the accuracy of identified themes and reported using selected quotes from participants.

\section{Results}

Feeding Practices for Infants and Young Children

While all of the group participants verbalized that it was better for babies to be breastfed, they did not all follow this practice. Reasons cited for not breast feeding included; "more convenient to bottle feed," "hard to breast feed once I returned to work", and "It is hard to do and not very convenient". Benefits of breast feeding verbalized by the group can be summed up in the following comment by one of the participants. "Breastfeeding makes the child smarter and healthier. They don't get fat if they are breastfed." Six of the study participants combined breast and bottle feeding. How study participants learned about breastfeeding varied; three participants reported learning from their mother, two learned from other family members, three from WIC staff, and two from health care providers. The reported length of time babies were breast fed varied from 6 months to 14 months with the average of 1 year. All of the group participants reported feeding their babies "bottles", ranging from formula to cows milk. The length of time reported for bottle feeding ranged from 1 year to 4 years with the majority of the group reporting that they bottle fed their babies for around 18 months.

Only one of the participants reported giving their babies or young children vitamins. A lack of understanding regarding the benefit of using vitamins or nutritional 
supplements was evident among the group. The majority of the group was under the impression that vitamins could increase the appetite of a "lazy eater". Three of the group participants reported that they gave their babies "fish oil to keep their digestive system working".

The next topic of discussion centered on the introduction of food to babies. Babies were first introduced food between 4 and 8 months of age with 5.5 months as the average reported age. The most common food initially fed to babies was rice cereal followed by "a little bit of vegetable soup mixed with smooched rice." None of the participants used commercially prepared baby food except rice cereal. They reported serving small portions of food that the family ate including vegetables, soup broth, meat, and fruit as long "as it was not fried". "It is really hard for young children to eat fried food. They get a belly ache." The group agreed that yogurt was also an appropriate food to feed a baby. Knowledge about Healthy Size and Weight and Ideal Diet for Young Children

The general consensus of the group was that children of all ages are healthy if "they are not fat" and "get enough exercise." Since all of these mothers participated in the WIC program they were familiar with height/weight charts for children and their children were weighed regularly at the WIC office or at their health care providers' office.

When discussing the appropriate diet for a young child (under the age of 6), the group consensus was that two meals a day consisting of "meat or fish with soup broth and vegetables with about a half cup of rice or noodles along with several snacks consisting of yogurt and fruit." The favorite sweet given to children was reported to be commercially packaged fruit snacks. The group also discussed the difference in appetites 
between girls and boys. One participant commented, "Because she's a girl, I don't want to push her too much about eating." In general, it was felt that boys ate more than girls. Knowledge about the Causes and Health Implications of Childhood Obesity

When asked about the causes of childhood obesity, study participants identified three major causes: “junk food"(“chips, fried pork rinds, McDonalds, coke”), high fat foods ("cheese and pizza"), and inactivity ("watching TV and playing video games"). The following comments typify the discussion. "Eating too much junk food and drinking too much soda makes kids fat." "My son was diagnosed as overweight in preschool. He is four and weighs 68 pounds. He is overweight because he drinks too much milk and watches too much TV. He lost weight when he started school because he started moving around.” Another participant commented, “My son gets mad at me if I don't give him soda and chips." Several of the study participants believed that if you do not engage in physical activity after eating, "fat storage increases."

There was a fair amount of discussion within the group about the difficulty in finding time to make sure their children got adequate exercise. Most of the mothers worked outside of the home and reported being "exhausted" by the time they got home in the evening. Study participants also reported that they actually got more exercise than their children on a daily basis. "I run around all day at work while my kids sit at home with my mother-in-law and watch TV and play video games."

All of the study participants agreed that is was not good or healthy for children to be overweight. "It can cause self esteem problems." "It is ugly to be fat and kids make fun of you." When discussing health problems associated with overweight and obesity, study participants identified diabetes, fatty liver, cardiovascular disease, bad back and 
slow intellectual development. "A big belly is bad for the back and I notice with my son that there is a delay in intellectual development due to his overweight." This comment was overwhelmingly supported by the group. "Overweight children have slow brain activity." One participant added, "Fat kids are lazy and they get tired easier and then do less thinking work."

\section{Limitations}

The convenience, nonprobability sample participating in this study was small and does not represent the broader population of Vietnamese immigrant mothers. The study participants all live in an urban area; therefore the findings described by the study group may not represent child feeding practices in rural areas. However, the findings from this study are an initial step in understanding child feeding practices of Vietnamese immigrant mothers. These findings informed the development of a culturally appropriate behavioral and educational intervention aimed at prevention of childhood obesity.

\section{Discussion}

The study participants identified that breastfeeding is healthier for babies than formula, but reported the difficulty maintaining breast feeding due to work and family constraints. A traditional Vietnamese diet (consisting of meat or fish with soup broth, vegetables and rice) was reported to be the preferred and healthiest diet for children under the age of six. There was consensus in the group that "junk food" and inactivity was unhealthy for children and led to overweight and obesity. Several of the group participants verbalized difficulty in maintaining a healthy diet for their children because the children demanded unhealthy food choices and their work schedules made it difficult to make sure their children were getting adequate exercise. 


\section{Recommendations for Future Research}

These findings have informed the development of a culturally appropriate behavioral and educational intervention aimed at primary prevention of childhood obesity in Vietnamese immigrants. This intervention is currently being tested with two groups of mothers. Interventions that consider the effects of acculturation will be more effective when targeted to parents of young children than interventions focused on treatment of obesity in later years.

\section{Clinical Implications}

It is important to continue to understand child feeding practices of different cultural groups as we develop and test interventions aimed at preventing childhood obesity. These findings will be particularly useful for nurses who care for immigrant families. Nurses caring for women during pregnancy are in key positions to teach their patients health feeding practices for infants and children. Pediatric nurses who care for children from different cultural backgrounds are also in a unique position to influence child feeding practices. By understanding the food preferences and traditional feeding practices of immigrant families, we can help families incorporate traditional foods into healthy eating practices for their children. Nurses who work with patients and families from different cultural backgrounds will be more successful if they understand cultural feeding practices and food preferences and incorporate those practices into teaching. 


\section{Suggested Clinical Implications}

Nurses working with immigrant women and children should:

Seek information from mothers on traditional infant and child feeding practices

Incorporate traditional feeding practices and food choices into nutritional teaching

Teach mothers healthy size and weights for children

Teach mothers the importance of good nutrition for their children

Support mothers in their efforts to promote healthy eating and exercise for their children 


\section{References Cited}

Birch, L., \& Fisher, J. (1998). Development of eating behaviors among children and adolescents. Pediatrics, 101 (3), 539-549.

Birch, L.L., \& Davidson. K.K. (2001). Family environmental factors influencing the developing behavioral controls of food intake and childhood overweight. Pediatric Clinics of North America, 48(4), 893-907.

Baruffi, G., Hardy, C.J., Waslien, C.I., Uyehara, S.J., \& Krupitsky, D. (2004). Ethnic differences in the prevalence of overweight among young children in Hawaii. Journal of the American Dietetic Association, 104(11), 1701-1707.

Bloor, M., Frankland, J., Thomas, M., \& Roson, K. (2001). Focus groups in social research. Thousand Oaks, CA: Sage.

Center for Disease and Prevention. (1998). Pediatric Nutrition Surveillance System Annual Report. Atlanta, GA: Maternal and Child Health Branch, Division of Nutrition.

Daniels, S.R. (2006). The consequences of childhood overweight and obesity. The Future of our Children, 16(1), 47-67.

Denzin, N.K., \& Lincoln, Y. (2000). Handbook of Qualitative Research. Thousand Oaks, CA: Sage.

Ebbleing, C.B., Pawlak, D.B., \& Ludwig, D.S. (2002). Childhood obesity: Public health crisis, common sense cure. Lancet, 360, 473-482.

French, S.A., Story, M., \& Perry, C.L. (1995). Self-esteem and obesity in children and adolescents: A literature review. Obesity Research, 3, 479-489.

Golan, M., Weizman, A., Apter, A., \& Fainara, M. (1998). Parents as the exclusive 
agents of change in the treatment of childhood obesity. American Journal of Clinical Nutrition, 67,1130-5.

Goran, M.I., Ball, G., \& Cruz, M.L. (2003). Obesity and risk of type 2 diabetes and cardiovascular disease in children and adolescents. The Journal of Clinical Endocrinology \& Metabolism, 88(4), 1417-1427.

Hernandes, D.J. (1999). Children of immigrants: Health, adjustment, and public Assistance. In D.J. Hernandez (Ed.), Children of immigrants: Health, adjustment, and public assistance (pp.1-17). Washington, D.D.: National Academy Press.

Janssen, I., Crawford, W.M., \& Boyce, W.F. (2004). Associations between overweight and obesity with bullying behaviors in school-aged children. Pediatrics, 113(5), 1187-1195.

Kidd, P., S., \& Parchall, M.,B. (2000). Getting the focus and the group: Enhancing analytical rigor in focus group research. Qualitative Health Research, 10(3), 293308.

Kumanyika, S., \& Grier, S. (2006). Targeting interventions for ethnic minority and low income populations. The Future of our Children, 16(1), 187-207.

Lindsay, A.C., Sussner, K.M., Kim, J., \& Gortmaker, S. (2006). The role of parents in preventing childhood obesity. The Future of our Children, 16(1), 169-186.

Lynn, M., R. (1986). Determination and quantification of content validity. Nursing Research, 35, 382-385.

McLafferty, I. (2004). Focus group interviews as a data collection strategy. Journal of Advanced Nursing, 48(2), 187-194.

Myers, S., \& Vargus, Z. (2000). Parental perceptions of the preschool obese child. 
Pediatric Nursing, 26(1), 23-30.

National Association of Pediatric Nurse Practitioner. (2006). Identifying and preventing overweight in childhood: clinical practice guidelines. Journal of Pediatric Health Care, 20(2), supplement.

Paxson, C., Donahue, C., Orleans, T., \& Grisso, J.A. (2006). Introducing the issue: Childhood obesity. The Future of Our Children, 16(1), 3-4.

Ritchies, L.,Welk, G., Styne, D., Gersteir, D., \& Crawford, P.B. (2005). Family Environment and Pediatric Overweight: What is a Parent to do? Journal of the American Dietetic Association, 105, S70-79.

Santora, M. (2006). East meets west, adding pounds and peril. New York Times 1/12/06

Retrieved February 8, 2007 from http://www.nytimes.com/2006/01/12/nyregion/nyregionspecial5/12diabetes.html?

Strauss, R.S. (2000). Childhood Obesity and Self-Esteem. Pediatrics, 105(1), 15-19.

Sturm, R. (2002). The effects of obesity, smoking, and drinking on medical problems and costs. Health Affairs, 21(2), 245-53.

Thorpe, L.E. et al., (2004). Childhood obesity in New York City elementary school students. American Journal of Public Health, 94(9), 1496-1500.

US Census Bureau. (2006). Percent of people who are foreign born: 2005 Universe: Total population. Retrieved February 12, 2007 from http://www.census.gov/population/socdemo/foreign/ppl-176/tab03-1.pdf US Census Bureau (2006). Census 2000 Demographic Profile Highlights: Selected Population Group: Vietnamese Alone. Retrieved February 12, 2007 from 
http://factfinder.census.gov/servlet/SAFFIteratedFacts?_event=\&geo_id=01000U S\&_geoContext $=01000 U S \& \_$street $=\& \_$county $=\& \_$cityTown $=\& \_$state $=\& \_z i p=\&$ _lang=en\&_sse $=$ on\&ActiveGeoDiv=\&_useEV=\&pctxt=fph\&pgsl=010\&_subme nuId=factsheet_2\&ds_name=DEC_2000_SAFF \&_ci_nbr=029\&qr_name=DEC_2 000_SAFF_R1010\&reg=DEC_2000_SAFF_R1010\%3A029\&_keyword=\&_indu stry $=$

Weicha J.M., Fink, A.K., Weicha, J. \& Herbert, J. (2001). Differences in dietary patterns of Vietnamese, White, African American, and Hispanic adolescents in Worchester, Mass.Journal of the American Dietetic Association, 101(2), 248-251. 